\title{
Influence of diaphragm flexibility on lateral load distribution between shear walls in light wood frame buildings
}

\author{
Z. Y. Chen ${ }^{1}$, Y. H. Chui ${ }^{1}$, C. Ni ${ }^{2}$, G. Doudak ${ }^{3}$ \& M. Mohammad ${ }^{2}$ \\ ${ }^{1}$ Faculty of Forestry and Environmental Management, \\ University of New Brunswick, Canada \\ ${ }^{2}$ Wood Products Division, FPInnovations, Canada \\ ${ }^{3}$ Department of Civil Engineering, University of Ottawa, Canada
}

\begin{abstract}
In light wood frame buildings, diaphragm flexibility influences the load distribution between shear walls under lateral load induced by earthquake or wind action, which is important for structural design. A multiple spring model with the ability to represent the load-transferring behaviour of this complex lateral load resisting system of light wood frame buildings was developed. The developed model was validated with results from the more sophisticated model, spring deep-beam model. The lateral load distribution between shear walls with various stiffness ratios of diaphragm to shear wall was also investigated. Based on preliminary findings from this study, contrary to common belief, the forces transferred by a semi-rigid diaphragm to the supporting shear walls, may be higher than those predicted by flexible and rigid diaphragm assumptions.

Keywords: light wood frame buildings, lateral load resisting system, diaphragm flexibility, load distribution.
\end{abstract}

\section{Introduction}

The lateral load resisting system (LLRS) of light wood frame building (LWFB) consists of wood-based shear walls and diaphragm (as shown in Figure 1). The shear walls resist the applied lateral load distributed by the horizontal diaphragm. The diaphragm flexibility relative to that of the supporting shear walls plays a key role in determining the load distribution between shear wall lines. If the 
diaphragm is deemed "flexible", the shear wall lines can be assumed to carry the lateral loads based on the tributary area method, while the lateral loads must be assigned to the shear walls in proportion to their stiffness if the diaphragm is "rigid". Therefore, it is important to quantify the flexibility of the diaphragm and the load distribution between shear wall lines when designing a LLRS.

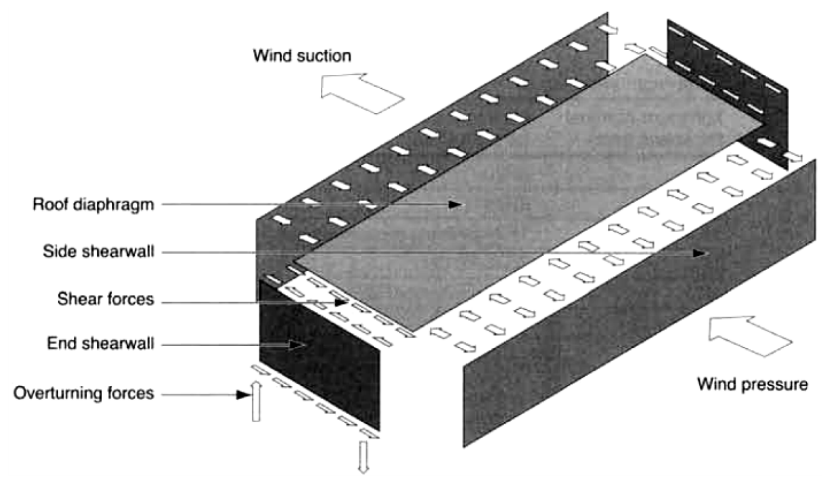

Figure 1: $\quad$ LLRS of LWFB [1].

Eurocode 8 [2], ASCE 07-10 [3] and ASCE 41-06 [4] provide criteria for diaphragm flexibility classes without any guidance on how to calculate the load distribution among the shear wall lines. To apply these classification criteria, numerical analysis needs to be carried out to determine deformations of diaphragms and LLREs under design load is required. Canadian timber design code, CSA O86-09 [5], does not provide specific guidelines on how to estimate the forces that flow to individual lateral load resisting element (LLRE). It is left to the discretion of the designers. A guideline document published by the Association of Professional Engineers and Geoscientists of British Columbia (APEGBC) [6] suggests that an envelope approach be used if the force in any shear wall is increased by more than $15 \%$ due to the change in the flexible and rigid diaphragm assumptions. This approach is simple and is thought to be conservative. However, as is shown in this paper, this approach may not always lead to conservative design forces.

To date, limited research has been performed to systematically evaluate the diaphragm flexibility and its influence on the lateral distribution of lateral load to shear walls of LWFB. In this study, a multiple spring model was developed. Based on this developed model, the lateral load distribution between shear wall lines of LWFBs with various stiffness ratios of diaphragm to shear wall was investigated as well.

\section{Springs model of LWFBs}

LWFB diaphragms are usually designed to behave elastically, so that they can sustain their function of transferring forces to the main LLREs, and maintain 
structural integrity. The spring deep-beam model (SDBM) can be used to represent the diaphragm-shear wall system where the shear walls are modelled as a series of springs and the diaphragm is modelled as an analogue beam which acts as a load distribution mechanism [7, 8]. The reaction forces in the springs of the SDBM can be calculated using simple mechanical theory. However, as the number of diaphragm elements and shear walls increases, it becomes more tedious to calculate the load distribution in shear wall lines using mechanical theory, and more sophisticated analysis procedures such as finite element analysis (FEA) may be required. For this reason, the SDBM is not considered to be designer friendly.

In the proposed multiple spring model, the elastic behaviour of a single-storey LWFB consisting of a floor diaphragm supported by a number of shear walls (Figure 2) can be represented by a series of linear springs, as shown in Figure 3.

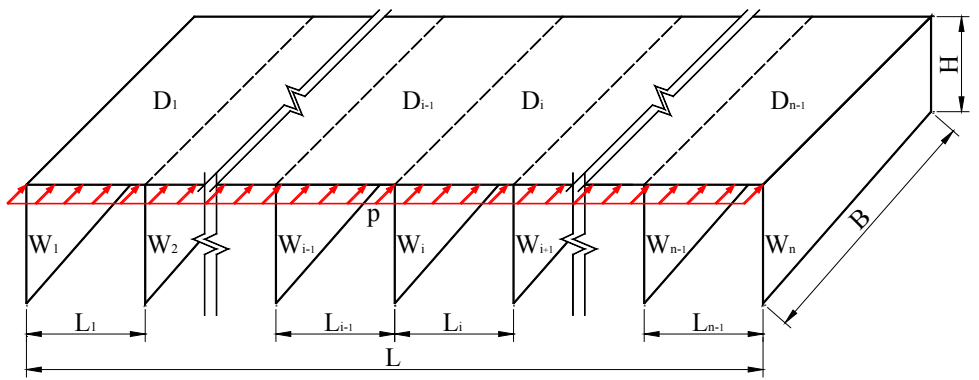

Figure 2: $\quad$ Single-storey LWFB with n LLREs.

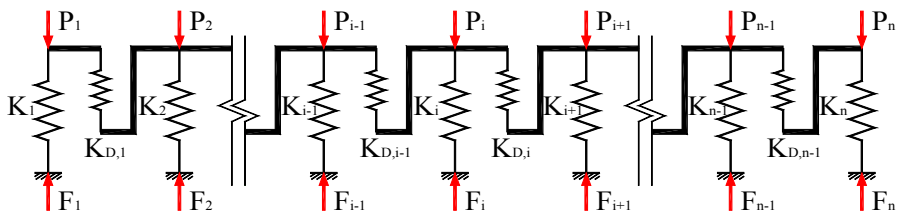

Figure 3: $\quad$ Multiple spring models for LWFB.

In the multiple spring model, each LLRE is represented by a spring connected to the ground, and the diaphragm between adjacent LLREs is represented by a spring connected to the springs of the two adjacent LLREs via a rigid beam with only one degree of freedom in the direction of load. The uniform load, $p$, is converted into a concentrated load, $P_{i}$, acting at the top of each LLRE based on the tributary area method.

The concentrated load equals to the product of the uniform load, $p$, and the tributary area, $A_{i}$, of the corresponding LLRE, as shown in eqn. (1).

$$
P_{i}=A_{i} p
$$

The lateral deformation of shear wall, $\Delta_{S W}$, and diaphragm, $\Delta_{D}$, can be calculated using eqns. (2) and (3) provided in CSA O86-09 [5]. 


$$
\Delta_{S W}=\frac{2 v H_{s}^{3}}{3 E A L_{s}}+\frac{v H_{s}}{B_{v}}+0.0025 H_{s} e_{n}+\frac{H_{s}}{L_{s}} d_{a}
$$

where $\Delta_{S W}$ is the horizontal in-plane deflection at top of the blocked single-storey shear wall segment; $v$ is the shear force per unit length due to specified lateral load, $\mathrm{N} / \mathrm{mm} ; H_{S}$ is the shear wall segment height, $\mathrm{mm} ; E$ is the modulus of elasticity of chords, $\mathrm{MPa} ; A$ is the cross-sectional area of chord members, $\mathrm{mm}^{2}$; $L_{S}$ is the length of shear wall segment, mm; $B_{V}$ is shear-through-thickness rigidity of sheathing panel, $\mathrm{N} / \mathrm{mm} ; e_{n}$ is nail deformation for a particular load per nail, $\mathrm{mm} ; d_{a}$ is total vertical elongation of the wall anchorage system at the induced shear load.

$$
\Delta_{D}=\frac{5 v L^{3}}{96 E A L_{D}}+\frac{v L}{4 B_{V}}+0.000614 L e_{n}+\frac{\sum\left(\Delta_{c} x\right)}{2 L_{D}}
$$

where $\Delta_{D}$ is the lateral deflection at mid-span of the simply supported blocked diaphragm, mm; $v$ is the shear force per unit length due to specified lateral loads, $\mathrm{N} / \mathrm{mm} ; L$ is diaphragm span perpendicular to the direction of the load, $\mathrm{mm} ; L_{D}$ is the depth of diaphragm parallel to the direction of the load, $\mathrm{mm}$; $\sum\left(\Delta_{C} x\right)$ is the sum of the individual chord-splice slip values, $\Delta_{C}$, on both sides of the diaphragm, each multiplied by its distance $x$ from the nearest support.

The stiffness of LLRE spring, $K_{i}$, can be taken as the reciprocal of the shear wall deformation under a unit load of $1 \mathrm{~N}$. The stiffness of diaphragm under uniform load similarly, is the reciprocal of the diaphragm deformation under a pressure of $1 / L_{i}\left(L_{i}\right.$ is the span of the $i$ th diaphragm, mm) $\mathrm{N} / \mathrm{mm}$, eqn. (4).

$$
K_{i}=1 / \Delta_{S W, i}
$$

The stiffness of diaphragm spring under a concentrated load, used in the multiple spring model, can be derived from the stiffness of diaphragm under uniform load using eqn. (5).

$$
K_{D, i}=\xi_{i} / \Delta_{D i}
$$

where $\xi$ is the conversion factor of diaphragm stiffness, by which the stiffness of diaphragm that behaves as a simply supported beam under a uniform load can be converted into the stiffness of diaphragm that behaves as a cantilever beam under a concentrated load at the tip, eqn. (6).

$$
\xi=\left[\frac{5 L}{96 E A L_{D}}+\frac{1}{4 B_{V}}\right] /\left[\frac{4 L}{3 E A L_{D}}+\frac{2}{B_{V}}\right]
$$

Regarding the multiple spring model, if the diaphragm is assumed flexible, the stiffness of the diaphragm spring, $K_{D i}$, is taken as zero, therefore, there will be no connection between the two adjacent LLRE springs (Figure 4a). The force in the LLRE spring, $F_{i}$, is proportional to the tributary area of the corresponding LLRE, eqn. (7a). When the diaphragm is assumed rigid, then $K_{D i}$ is taken as 
infinity (Figure $4 \mathrm{~b}$ ), and each shear wall carries the load, $F_{i}$, in proportion to the relative stiffness of the LLREs, eqn. (7b).

$$
\begin{aligned}
& F_{i} \propto \alpha_{A i}=A_{i} / \sum_{i=1}^{n} A_{i} \\
& F_{i} \propto \alpha_{K i}=K_{i} / \sum_{i=1}^{n} K_{i}
\end{aligned}
$$

where $\alpha_{A i}$ and $\alpha_{K i}$ are the tributary area ratio and stiffness ratio, respectively.

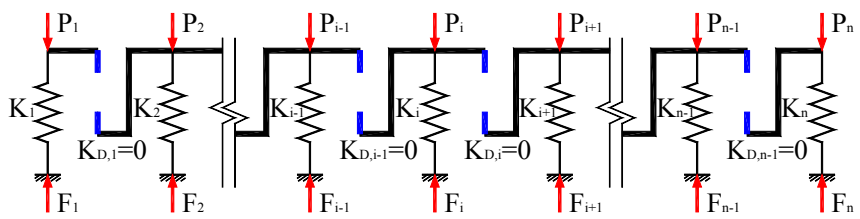

(a) Flexible diaphragm case

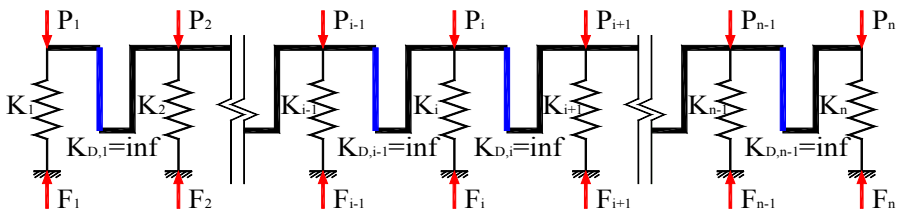

(b) Rigid diaphragm case

Figure 4: $\quad$ Two extreme cases of multiple spring model.

The reactions and deformations of LLRE springs in this spring model with semi-rigid diaphragm shown in Figure 3 can be obtained by solving the system of equations with $2 \mathrm{n}$ variables, as shown in eqn. (8).

$$
\{F\}_{2 n}=[D]_{2 n \times 2 n}\{U\}_{2 n}
$$

where,

$$
\begin{gathered}
F_{i}=\left\{\begin{array}{ccc}
F_{(i+1) / 2} & i-\text { odd } \\
-P_{i / 2} & i-\text { even }
\end{array}\right. \\
D_{i j}=\left\{\begin{array}{cccc}
K_{(i+1) / 2} & j=i \quad \& \quad i-\text { odd } \\
K_{i / 2}+K_{D,(i / 2-1)}+K_{D, i / 2} & j=i \quad \& \quad i-\text { even } \\
-K_{(i+1) / 2} & j=i+1 \quad \& \quad i-\text { odd } \\
-K_{i / 2} & j=i-1 \quad \& \quad i-\text { even } \\
-K_{D, i / 2} & j=i+2 \quad \& \quad i-\text { even } \\
-K_{D,(i-2) / 2} & j=i-2 \quad \& \quad i-\text { even } \\
0 & \text { others }
\end{array}\right.
\end{gathered}
$$


162 Earthquake Resistant Engineering Structures IX

$$
U_{i}=\left\{\begin{array}{cc}
0 & i-\text { odd } \\
u_{i / 2} & i-\text { even }
\end{array}\right.
$$

\section{Load distribution of LWFBs}

In order to verify the proposed multiple spring model and to investigate the load distribution between shear wall lines, three cases of single-storey LWFB with different shear wall arrangements were analysed under a uniform lateral load, as shown in Figure 5. Only two types of shear walls with a length ratio of 0.5 were used. The shear wall stiffness is assumed to be proportional to its length.

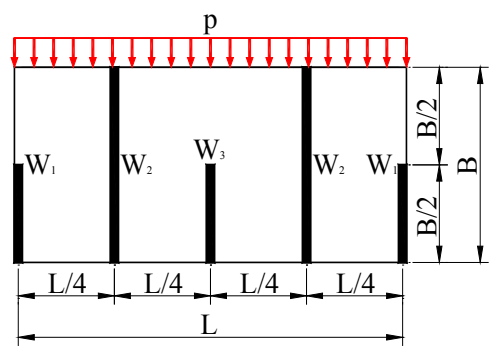

(a) Case I

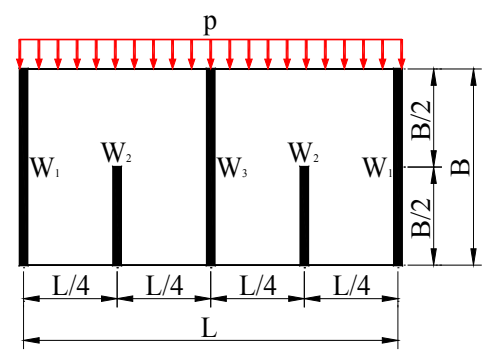

(b) Case II

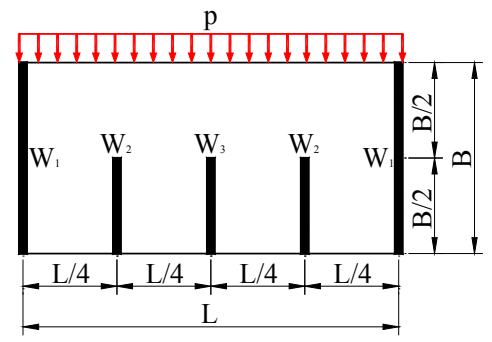

(c) Case III

Figure 5: Three cases of LWFB with different layout. 
The SDBM, as shown in Figure 6a, was used as the reference analysis method. Three finite element (FE) models (Figure 6b), in which the deep beam was simulated by four hundred two-dimensional Timoshenko beam elements, B21, and shear wall springs were modeled using five spring elements, SPRING2, acting in a fixed direction (Y), were developed using FE software, ABAQUS [9]. Due to the symmetry of building model and loading condition, symmetrical reactions were obtained, as shown in Figure 6b. By increasing or decreasing equivalent stiffness of diaphragm, $K_{D}$, the sensitivity of load distribution and deformation ratio to diaphragm flexibility can be investigated.

The force ratios, $\alpha_{F}$, of the FEA are compared with ratios of reactions calculated from the multiple spring model using eqn. (8), as shown in Figure 7. The force ratios of the three LWFB cases predicted by the multiple spring model at extreme diaphragm stiffness values agree with those predicted by FEA. There are larger discrepancies for semi-rigid diaphragm, but the maximum deviation is only about $20 \%$. This level of discrepancy is considered acceptable for structural design purposes, indicating that the multiple spring model is appropriate to estimate the load distribution between shear wall lines in LWFBs. While finding a solution to a system consisting of more than 3 shear walls may be tedious, the solution procedure for eqn. (8), which forms the theoretical basis of the multiple spring model, can be easily implemented in a simple computer program.

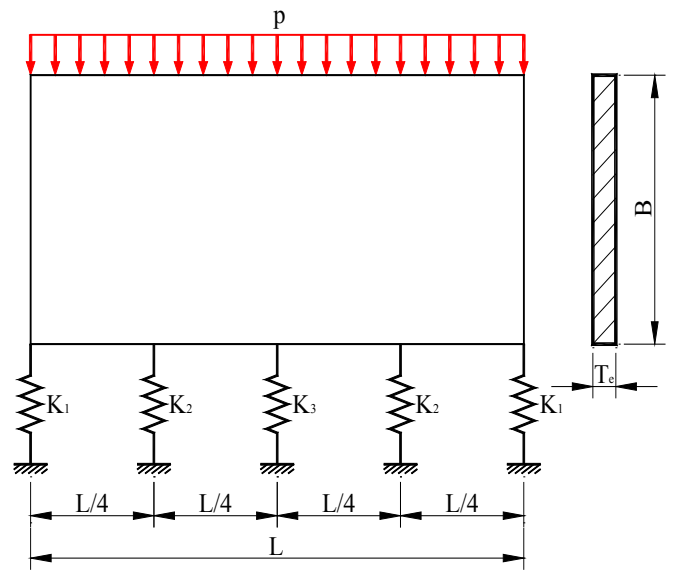

(a) Mechanical model

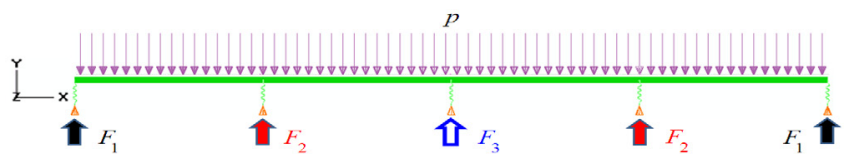

(b) FE model

Figure 6: SDBMs of LWFBs.

In addition, an interesting and unexpected phenomenon was observed in the results shown in Figure 7. One force ratio of internal spring, $\alpha_{F 2}$ of case I and $\alpha_{F 3}$ 
164 Earthquake Resistant Engineering Structures IX

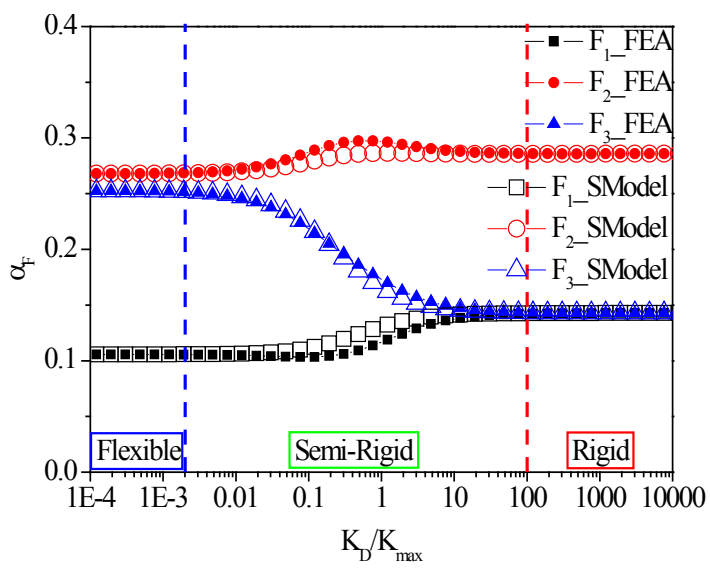

(a) Case I

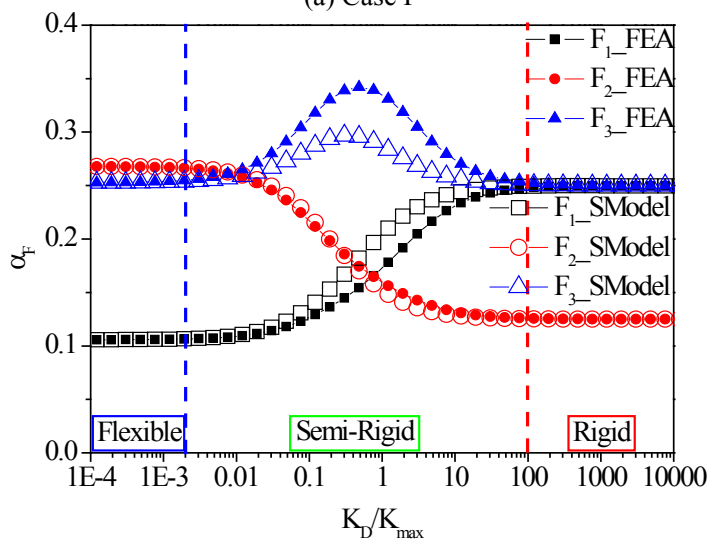

(b) Case II

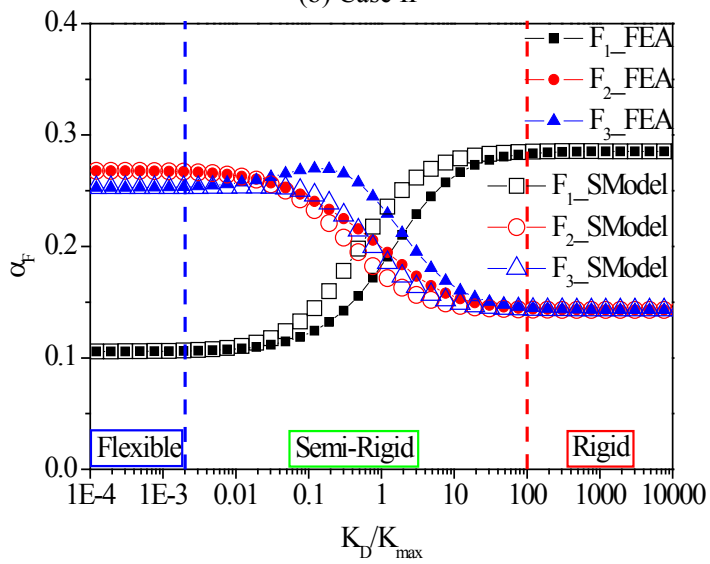

(c) Case III

Figure 7: $\quad$ Force ratio vs. stiffness ratio. 
of cases II and III, in the semi-rigid range, is higher than the two extreme values when stiffness ratio approaches zero and infinity, respectively. This phenomenon is observed in both the multiple spring model and the FEA results. This is thought to be induced by deformation compatibility that occurs in continuous beams. Therefore, the design method using the envelope forces of the two diaphragm flexibility assumptions, as proposed in reference [6], is not always conservative. Therefore, the multiple spring model proposed in this paper can be used to estimate the actual forces carried by the LLREs with any diaphragm, without conducting FEA using the SDBM.

\section{Conclusions}

The load distribution between shear wall lines plays an important role in the structural design of LWFBs. However there has not been any accepted procedure to accurately calculate this load distribution for design use. In this paper a simplified, and yet mechanically sound, model consisting of multiple springs to represent the stiffness of diaphragms and supporting shear walls, is proposed. This model can be implemented in a simple computer program. Comparison of prediction results with those obtained from SDBM using FEA has shown that the proposed model is adequate for design use. In addition, the results shown here reveal that the design method based on envelope forces (i.e. taking the larger of the shear wall force based on either flexible or rigid diaphragm) is not always conservative.

The results presented in this paper provide the foundation for further work to develop a more robust, designer-useable method of predicting load distribution to shear walls based on ratio of diaphragm stiffness to that of the shear walls supporting it. Further work will include: (a) simplification of the multiple spring model to circumvent the need to use a computer program; (b) expanding the method of classifying diaphragm flexibility from single-storey to multi-storey buildings; (c) extending this method to a general method for timber buildings, such as massive timber systems.

\section{Acknowledgements}

The authors greatly acknowledge the financial support provided by Natural Sciences and Engineering Research Council (NSERC) of Canada under the Strategic Research Network on Innovative Wood Products and Building Systems (NEWBuildS).

\section{References}

[1] Canadian Wood Council, Wood Design Manual 2010. Eton System: Nepean, 2010.

[2] CEN, EN 1998-1:2004/A1:2013 Eurocode 8: Design of Structures for Earthquake Resistance - Part 1: General Rules, Seismic Actions and Rules 
for Buildings. European Committee for Standardization (CEN): Brussels, 2013.

[3] ASCE, Minimum Design Loads for Buildings and Other Structures. American Society of Civil Engineering (ASCE): Reston, 2010.

[4] ASCE, ASCE 41-06 Seismic Rehabilitation of Existing Buildings. American Society of Civil Engineering (ASCE): Reston, 2006.

[5] CSA, O86-09: Engineering Design in Wood. Canadian Standards Association (CSA): Toronto, 2009.

[6] APEGBC, Structural, Fire Protection and Building Envelope Professional Engineering Services for 5 and 6 Storey Wood Frame Residential Building Projects (Mid-Rise Buildings). Professional Engineers and Geoscientists of BC (APEGBC) Technical and Practice Bulletin. http://www.apeg.bc.ca/pp ractice/documents/ppguidelines/5and6StoreyWoodFrameBulletin.pdf

[7] Pang, W.C. \& Rosowsky, D., Beam-Spring Model for Timber Diaphragms and Shear Walls. Structures and Buildings, 163(SB4), pp. 227-244, 2010.

[8] Chen, Z.Y., Chui, Y.H., Ni, C. \& Xu, J., Seismic Response of Mid-Rise Light Wood Frame Buildings with Portal Frames. Journal of Structural Engineering. (Accepted)

[9] ABAQUS, ABAQUS Analysis User's Manual (Version 6.11). Hibbitt, Karlsson, and Sorenson: Pawtucket, R.I., 2011. 